\title{
Resistance Training in Parkinson's Disease: A Longitudinal Study
}

\author{
Luca Beratto1, Federico Abate Daga², Ruben Allois³ ${ }^{3}$ Massimiliano Gollin ${ }^{*}$ \\ ${ }^{1}$ Experimental Medicine and Therapy, Motor Science Research Center, Adapted Training and Performance Laboratory, University \\ of Turin, Turin, Italy \\ ${ }^{2}$ Medical Physiopathology, Motor Science Research Center, Adapted Training and Performance Laboratory, University of Turin, \\ Turin, Italy \\ ${ }^{3}$ University School of Motor \& Sport Sciences Graduate, University of Turin, Turin, Italy \\ ${ }^{4}$ Department of Clinical and Biological Sciences, Motor Science Research Center, Adapted Training and Performance Laboratory, \\ University of Turin, Turin, Italy \\ Email: *massimiliano.gollin@unito.it
}

How to cite this paper: Beratto, L., Daga, F.A., Allois, R. and Gollin, M. (2017) Resistance Training in Parkinson's Disease: A Longitudinal Study. Advances in Parkinson's Disease, 6, 67-74.

https://doi.org/10.4236/apd.2017.62007

Received: March 25, 2017

Accepted: May 16, 2017

Published: May 19, 2017

Copyright $\odot 2017$ by authors and Scientific Research Publishing Inc. This work is licensed under the Creative Commons Attribution International License (CC BY 4.0). http://creativecommons.org/licenses/by/4.0/

\begin{abstract}
Objective: The objective of this study was to verify the effect of micro-loads and elastic bands exercise program in a group of patients with Parkinson's disease (PD). Methods: Twenty-one people with PD, participated in this study. All participants were able to walk unassisted, and their disability score using the Hoehn \& Yahr scale was $2 \pm 0.5$. Subjects were randomly assigned to micro-loads group (11 subjects, age $69 \pm 10$ years; weight $72 \pm 12 \mathrm{~kg}$, height $171 \pm 7 \mathrm{~cm}$ ) or to elastic band group ( 9 subjects, age $70 \pm 11$ years; weight $69 \pm 15 \mathrm{~kg}$ and high $169 \pm 9$ $\mathrm{cm})$. Both groups performed two sessions of physical activity per week during a period of 5 months. Subjects were evaluated on flexibility with sit and reach test; the body balance with stabilometric platform, useful to evaluate the center of pressure (COP); the Spinal Mouse ${ }^{\circledR}$ to assess the column shape and the sit to stand test to measure the strength performance of lower limbs. Tests were three times during the training period: after the first and the third month of physical activity and at the end of the training period. Results: Data showed a statistically significant variation in the sit to stand test in the EG group $\left(\mathrm{T}_{0}\right.$ vs $\mathrm{T}_{2}$; Anova, $\mathrm{p}<$ 0.001 , post hoc, $\mathrm{p}<0.01,+19 \%)$. Conclusion: Both micro-loads and elastic band exercises were well-tolerated. Elastic bands exercises produced a significant improvement in the lower limbs muscles performance.
\end{abstract}

\section{Keywords}

Parkinson, Exercise, Strength, Longitudinal

\section{Introduction}

Parkinson's disease (PD) is a neurodegenerative disorder characterized by rigi- 
dity, tremor, bradykinesia and postural instability. Adapted physical activity (APA) is useful to reduce the physical inefficiency caused by Parkinson's disease [1] [2] [3]. The maintenance of a muscle-joint structure functional level seems to be the only way to preserve the residual motor abilities and to slow disability progression process, that relentless influences quality of life. Body response to physical activity in Parkinson's Disease is slow, because of biological aging [4], so an appropriate training program should be continued for at least six-month [5]. It was demonstrated that Nordic walking is well tolerated by subjects with PD, improving body balance, gait cycle and lower limbs strength [6]. Resistance strength training [7] has positive effects in maintaining body posture [8]. Multi-joint isometric exercises are able to improve lower limbs functionality [9]. Several studies have demonstrated that aerobic endurance workout on treadmill positively influences lower limb motor tasks [10], increases oxygen consumption and improves movement economy [11]. In addition, walking with an additional overweight enhance body balance [12]. Furthermore Yang et al. [7] investigated as downhill walking training (slope between $3 \%$ and $8 \%$ ) is useful to improve posture trunk and create a positive effect on knee extensor muscle strength.

Finally, one of the recurrent disorders of PD is the freezing of gait [13]. Emphasis on this deficit is caused by a reduction of the hamstring muscle-tendon flexibility combined with lower limbs strength and coordination decrease [14]. So, basing on what literature said, the aim of this study was to investigate whether a protocol of overweight exercises (applied on wrist and ankle) compared with exercises performed thought elastic bands might cause changes in physical efficiency in subjects with PD.

\section{Materials and Methods}

Twenty-one PD subjects volunteers, able to walk unassisted with a disability score using the Hoehn \& Yahr scale [15] of $2 \pm 0.5$ were recruited for this study. Subjects were randomly assigned to Micro-loads Group (11 subjects, age $69 \pm 10$ years; weight $72 \pm 12 \mathrm{~kg}$, height $171 \pm 7 \mathrm{~cm}$ ) or to Elastic band Group (9 subjects, age $70 \pm 11$ years; weight $69 \pm 15 \mathrm{~kg}$ and high $169 \pm 9 \mathrm{~cm}$ ). As shown in Figure 1, two sessions of physical activity per week were performed. Both group executed the same exercises schedule but the first group completed it using micro-loads applied on wrists and ankles, while the second one exercises themselves with elastic bands. Before starting our 5 month training program, all people were informed about the purpose of the study and signed an informed consent.

Both groups were measured three times during training period:

- After the first training month $\left(\mathrm{T}_{0}\right)$. In this period subjects learned exercises technique, their basal physical condition was identified and exercises intensity was set basing on the results of this evaluation.

- After two months from $\mathrm{T}_{0}$, to verify the effects caused by the first two training months $\left(\mathrm{T}_{1}\right)$. 


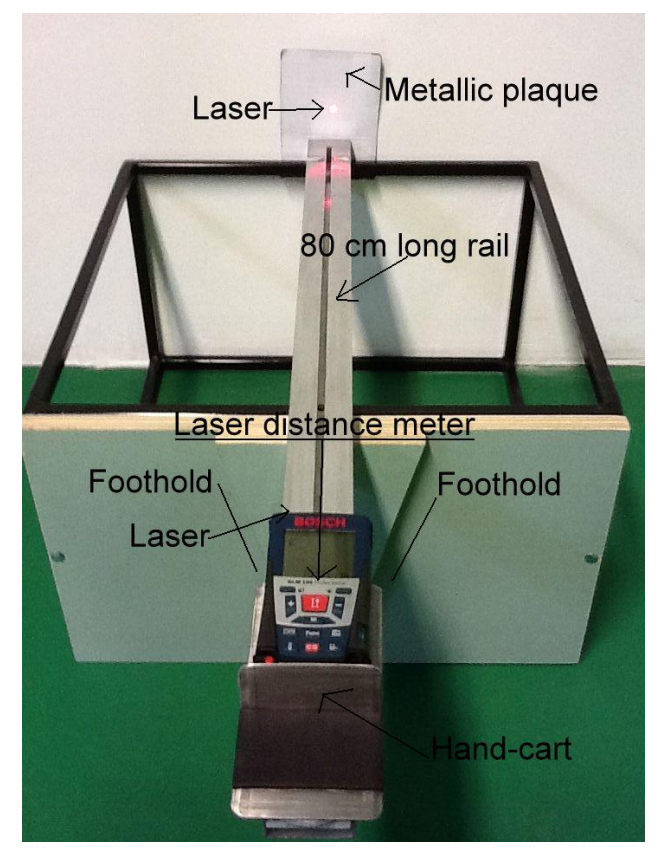

Figure 1. Sit and reach.

- After 2 months from $T_{1}$, to verify the effects caused by the first four training months $\left(\mathrm{T}_{2}\right)$.

The parameters investigated were: 1) posture and flexibility of spine and hamstring muscle; 2) the body balance in upright position, and 3) the strength of the lower limbs.

\section{Devices and Test Protocol}

\subsection{Sit and Reach Test}

This test, consisting in a forward torso flexion from sitted position with extended legs. It was performed on a new sit and reach box, in which a digital distance meter $( \pm 1 \mathrm{~mm})$ was installed (Bosch, Germany). (Figure 1). This device provides more accurate measures respect a traditional sit and reach box. For this reason, it was chosen for this study.

\subsection{Stabilometric Test}

Static posturography (Figure 2) is used to asses balance capacity in patients with nervous system disease [16]. This test was performed with stabilometric platform (Prokin, Tecnoboby Bergamo, Italy). Centre of Pressure (CoP) positions were computed to calculate the following variables:

Length $[\mathrm{mm}]$ : length of CoP trajectory computed as sum of CoP displacement on the platform surface;

Area $\left[\mathrm{mm}^{2}\right]$ : elliptical area computed as CoP trajectory

Sway AP and ML [mm]: standard deviation of CoP along anterior-posterior (Sway AP) and medio-lateral (Sway ML) axes;

Velocity AP and ML $[\mathrm{mm} / \mathrm{s}]$ : velocity of oscillations along anterior-posterior (Vel AP) and medio-lateral (Vel ML) axes. 
Participants will perform the following stabilometric test with 1 minute of rest between the two test:

1) A bipodalic test with eyes open (OA) lasting 30 seconds;

2) A bipodalic test with eyes closed (OC) lasting 30 seconds.

\subsection{Morphological Evaluation of Vertebral Column}

The vertebral column morphology evaluation is obtained using the Spinal Mouse $^{\circledR}$ (Idiag, Voletswil, Switzerland) on sagittal planes [17]. The Spinal Mouse $^{\circledR}$ (Figure 3 ) measures the length $(\mathrm{mm})$ and the angle (degrees) of the column.

The Spinal Mouse ${ }^{\circledR}$ allows to measure thoracic segment (ThSp), between the first (ThSp1) and the last thoracic vertebra (ThSp12), lumbar segment (LSp) between ThSp12 to first sacral vertebra S1, the inclination (Incl) as the slope of connection line between S1 and ThSp1. In the sagittal plane the vertebral column is evaluated in three positions:

1) Standing upright (in relaxed position, focusing on a marker at eye level, feet aligned with shoulders, knees straight, arms along the trunk).

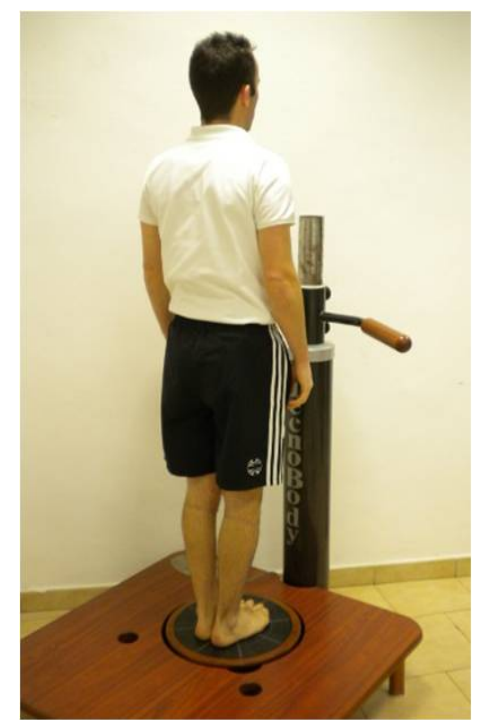

Figure 2. Stabilometric platform.

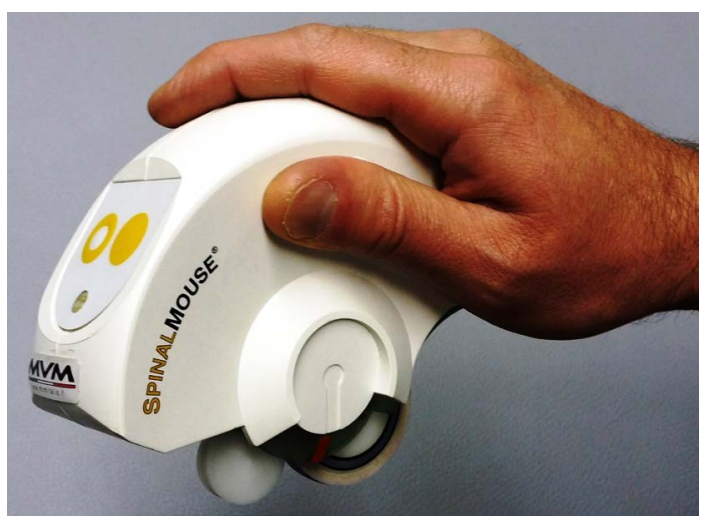

Figure 3. Spinal Mouse ${ }^{\circledR}$. 
2) Maximal flexion (legs extended, trunk bent forward in an attempt to reach the floor).

3) Maximal extension (legs extended, arms crossed over the chest, chin against the sternum, trunk extended backwards).

\subsection{Sit to Stand Test}

The test consists in measuring the maximum number of times that the subject sits down and stands up in 30 seconds (Figure 4) [18]. An Optojump ${ }^{\circledR}$ (Microgate, Italy) was used to identified the number of movements that subjects done.

\subsection{Exercises Protocol}

Both MG and EG trained on the same muscles and for the same amount of time but with different fitness tools. MG used overweight applied on wrists and ankles while EG stimulated muscles using elastic bands. Exercises targets were: 1) to stimulate muscle-joint structure multilateralism; 2) to exercise monotony; 3) to keep the sample groups interested into activity program. Both MG (Table 1) and EG (Table 2), started stimulating resistance training (20 repetitions) and continuing progressively towards the stimulation of muscular strength (10 and 15 repetitions). Both groups performed 2 set within 2 minutes rest between sets.

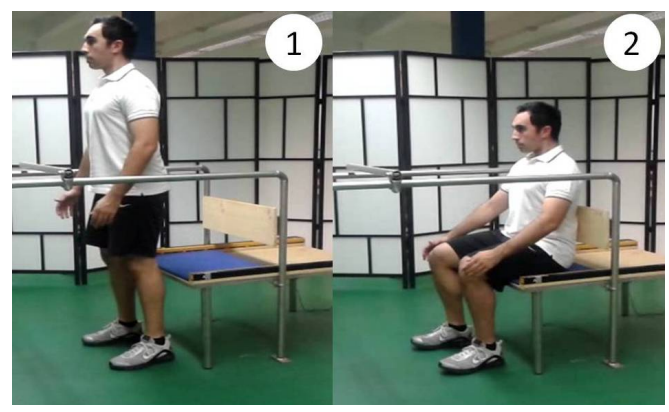

Figure 4. Sit To Stand Test: 1) Starting position; 2) Final position.

Table 1. Training program MG.

\begin{tabular}{ccc}
\hline & Training Program MG & Muscle \\
\hline 1 & Warm up: 10 minutes of walking exercises & \\
2 & Crunch & Abdominal \\
3 & Dumbbell Flyes & Pectoral \\
4 & Dumbbell Rowing & Latissimus Dorsis \\
5 & Upright row & Trapezius \\
6 & Hammer curl & Biceps \\
7 & Palms up with wooden bar & Foreams \\
8 & Front raise with Dumbbell & Deltoids \\
9 & French press & Triceps \\
10 & Squat & Quadriceps \\
11 & Standing Calf & Sural Tricipes \\
\hline
\end{tabular}


Table 2. Training program EG.

\begin{tabular}{ccc}
\hline & Training Program EG & Muscle \\
\hline 1 & Warm up: 10 minutes of walking exercises & \\
2 & Crunch & Abdominal \\
3 & Bench press with elastic band & Pectoral \\
4 & Rower seating with elastic band & Latissimus dorsis \\
5 & Shrugs & Trapezius \\
6 & Hammer Curl th elastic band & Biceps \\
7 & Palms up with wooden bar & Foreams \\
8 & Push down with elastic band & Tricipes \\
9 & Lateral raise & Deltoids \\
10 & Squat with elastic band & Quadriceps \\
11 & Standing Calf & Sural Tricipes \\
\hline
\end{tabular}

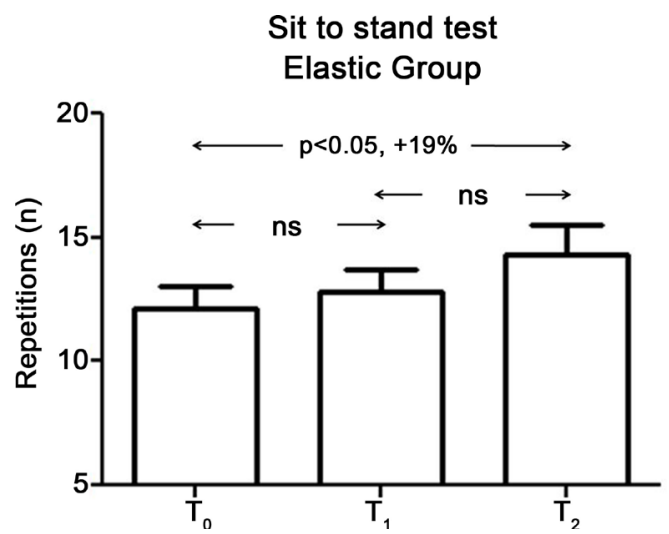

Figure 5. Sit to stand EG.

\subsection{Statistical Analysis}

The following statistical tests were used: Friedman ANOVA; Dunn post-hoc. Percentages differences were calculated with the following formula: ((Fv-Iv)/Iv) $\times 100 ; \mathrm{Fv}$ is final value and $\mathrm{Iv}$ is initial value. The significance was fixed at $\mathrm{P}=$ 0.05. Each analysis was carried out using the GraphPad software (GraphPad Software, Inc., USA).

\section{Results}

All participants completed the exercise program without any negative effects and were able to manage the progressive exercise difficulty increment during the entire period of the study. As shown in Figure 5, there was a significant increase in sit to stand test (STS) in elastic group $\left(\mathrm{T}_{0}\right.$ vs $\mathrm{T}_{2}$; Friedman ANOVA, $\mathrm{p}<0.001$, post hoc, $\mathrm{p}<0.01,+19 \%)$. No significant change was observed in the MG.

\section{Discussion}

This study has shown that a 4-months elastic bands exercise program is useful to 
PD patients. Data analysis highlight a statistically significant positive improvement in EG on the Sit to Stand test. This result underlines that a progressive workout with elastic bands increase lower limbs muscle strength outcomes. Furthermore, this findings suggest that these kind of exercises with elastic band might improve the subject functionality in daily activities. No statistically significant variation of the parameters investigated was found on MG.

\section{Conclusion}

Both micro-loads and elastic band exercises were well tolerated by patients with PD and nobody denounced problem insurgence during activity. The study highlights the positive effect of a longitudinal muscle strength training program in the lower limbs strength.

\section{References}

[1] Iva, M. (2017) The Effects of Exercise on People with Parkinson's Disease-Review. Advances in Parkinson's Disease, 6, 24-38. https://doi.org/10.4236/apd.2017.61003

[2] Kurlan, R., Evans, R., Wrigley, S., McPartland, S., Bustami, R. and Cotter, A. (2015) Tai Chi in Parkinson's Disease: A Preliminary Randomized, Controlled, and RaterBlinded Study. Advances in Parkinson's Disease, 4, 9-12.

https://doi.org/10.4236/apd.2015.41002

[3] Johnson, L., Putrino, D., James, I., Rodrigues, J., Stell, R., Thickbroom, G. and Mastaglia, F.L. (2013) The Effects of a Supervised Pilates Training Program on Balance in Parkinson's Disease. Advances in Parkinson's Disease, 2, 58-61. https://doi.org/10.4236/apd.2013.22011

[4] Crizzle, A. and Newhouse, I. (2006) Is Physical Exercise Beneficial for Persons with Parkinson's Disease? Clinical Journal of Sport Medicine, 16, 422-425.

[5] Sinaki, M., Nwaogwugwu, N., Phillips, B. and Mokri, M. (2001) Effect of Gender, Age, and Anthropometry on Axial and Appendicular Muscle Strength. American Journal of Physical Medicine \& Rehabilitation, 80, 330-338. https://doi.org/10.1097/00002060-200105000-00002

[6] Reuter, I., Mehnert, S., Leone, P., Kaps, M., Oechsner, M. and Engelhardt, M. (2011) Effects of a Flexibility and Relaxation Programme, Walking, and Nordic Walking on Parkinson's Disease. Journal of Aging Research, 2011, Article ID: 232473. https://doi.org/10.4061/2011/232473

[7] Yang, Y., Lee, Y., Cheng, S. and Wang, R. (2010) Downhill Walking Training in Individuals with Parkinson's Disease: A Randomized Controlled Trial. American Journal of Physical Medicine \& Rehabilitation, 89, 706-714.

https://doi.org/10.1097/PHM.0b013e3181e721c5

[8] Falvo, M.J., Schilling, B.K. and Earhart, G.M. (2008) Parkinson's Disease and Resistive Exercise: Rationale, Review, and Recommendations. Movement Disorders, 23, 1-11. https://doi.org/10.1002/mds.21690

[9] Schilling, B.K., Karlage, R.E., LeDoux, M.S., Pfeiffer, R.F., Weiss, L.W. and Falvo, M.J. (2009) Impaired Leg Extensor Strength in Individuals with Parkinson Disease and Relatedness to Functional Mobility. Parkinsonism \& Related Disorders, 15, 776-780. https://doi.org/10.1016/j.parkreldis.2009.06.002

[10] Kurtais, Y., Kutlay, S., Tur, B.S., Gok, H. and Akbostanci, C. (2008) Does Treadmill Training Improve Lower-Extremity Tasks in Parkinson Disease? A Randomized Controlled Trial. Clinical Journal of Sport Medicine, 18, 289-291. 
https://doi.org/10.1097/JSM.0b013e318170626d

[11] Schenkman, M., Hall, D., Baro, A., Schwartz, R., Mettler, P. and Kohrt, W. (2012) Exercise for People in Early- or Mid-Stage Parkinson Disease: A 16-Month Randomized Controlled Trial. Physical Therapy, 92, 1395-1410. https://doi.org/10.2522/ptj.20110472

[12] Filippin, N.T., da Costa, P.H. and Mattioli, R. (2010) Effects of Treadmill-Walking Training with Additional Body Load on Quality of Life in Subjects with Parkinson's Disease. Revista Brasileira de Fisioterapia, 14, 344-350. https://doi.org/10.1590/S1413-35552010005000016

[13] Spildooren, J., Vercruysse, S., Meyns, P., Vandenbossche, J., Heremans, E., Desloovere, K., Vandenberghe, W. and Nieuwboer, A. (2012) Turning and Unilateral Cueing in Parkinson's Disease Patients with and without Freezing of Gait. Neuroscience, 207, 298-306. https://doi.org/10.1016/j.neuroscience.2012.01.024

[14] Allen, N.E., Sherrington, C., Canning, C.G. and Fung, V.S. (2010) Reduced Muscle Power Is Associated with Slower Walking Velocity and Falls in People with Parkinson's Disease. Parkinsonism \& Related Disorders, 16, 261-264. https://doi.org/10.1016/j.parkreldis.2009.12.011

[15] Goetz, C., Poewe, W., Rascol, O., Sampaio, C., Stebbins, G., Counsell, C., Giladi, N., Holloway, R., Moore, C., Wenning, G., Yahr, M. and Seidl, L. (2004) Movement Disorder Society Task Force Report on the Hoehn and Yahr Staging Scale: Status and Recommendations. Movement Disorders, 19, 1020-1028. https://doi.org/10.1002/mds.20213

[16] Cortesi, M., Cattaneo, D. and Jonsdottir, J. (2011) Effect of Kinesio Taping on Standing Balance in Subjects with Multiple Sclerosis: A Pilot Study. NeuroRehabilitation, 28, 365-372.

[17] Mannion, A., Knecht, K., Balaban, G., Dvorak, J. and Grob, D. (2004) A New SkinSurface Device for Measuring the Curvature and Global and Segmental Ranges of Motion of the Spine: Reliability of Measurements and Comparison with Data Reviewed from the Literature. European Spine Journal, 13, 122-136. https://doi.org/10.1007/s00586-003-0618-8

[18] Milanović, Z., Pantelić, S., Trajković, N., Sporiš, G., Kostić, R. and James N. (2013) Age-Related Decrease in Physical Activity and Functional Fitness among Elderly Men and Women. Clinical Interventions in Aging, 8, 549-556.

https://doi.org/10.2147/CIA.S44112

\section{Scientific Research Publishing}

\section{Submit or recommend next manuscript to SCIRP and we will provide best service for you:}

Accepting pre-submission inquiries through Email, Facebook, LinkedIn, Twitter, etc. A wide selection of journals (inclusive of 9 subjects, more than 200 journals) Providing 24-hour high-quality service User-friendly online submission system Fair and swift peer-review system Efficient typesetting and proofreading procedure Display of the result of downloads and visits, as well as the number of cited articles Maximum dissemination of your research work

Submit your manuscript at: http://papersubmission.scirp.org/ Or contact apd@scirp.org 